\title{
Sociodemographic Profile of CSOM- A Hospital Based Prospective Study
}

\author{
Surajit Basumatari ${ }^{1}$, Bikashjyoti Rajbangshi ${ }^{2}$ \\ ${ }^{1}$ Associate Professor, Department of ENT, FAAMCH, Barpeta, Assam, India. \\ ${ }^{2}$ Junior Resident, Department of ENT, FAAMCH, Barpeta, Assam, India.
}

\section{ABSTRACT}

\section{BACKGROUND}

Chronic suppurative otitis media (CSOM) is one of the most common ear conditions in developing countries particularly in south-east Asian countries. Chronic otitis media has been an important disorder of middle ear causing morbidity and mortality even with the advent of newer antibiotics and better health facilities. Chronic Suppurative Otitis Media accounts for 28,000 deaths and a disease burden of over 2 million DALYs. Over $90 \%$ of the burden is borne by countries in the southeast Asia and western Pacific regions, Africa, and several regions in the Pacific Rim affecting both the sexes \& all age groups. Risk factors that have been attributed to the high rates of Chronic Suppurative Otitis Media in these populations are: overcrowding, poor hygiene, poor nutrition, high rates of nasopharyngeal colonization with potentially pathogenic bacteria and inadequate and unavailable health care. With the greater advent of diagnostic tools, it has become easier to diagnose and classify different types of chronic otitis media. Similarly, with easier availability of medicines and advanced surgical procedures. the management of chronic otitis media has become easier. However, in developing nations like India, particularly in lower Assam district of Barpeta and surrounding areas, Chronic Suppurative Otitis Media still accounts for major percentage of patients attending ENT OPD of Fakhruddin Ali Ahmed Medical College and Hospital. Therefore, this study aims to study the clinical profile of the patients of Chronic Suppurative Otitis Media and to analyse the epidemiological factors associated with Chronic Suppurative Otitis Media.

\section{METHODS}

This is a cross sectional study conducted in the department of ENT, Fakhruddin Ali Ahmed Medical College, Barpeta for a period of one year from 1 $1^{\text {st }}$ January 2018 to 31 ${ }^{\text {st }}$ December 2018 in 180 diagnosed cases of Chronic Suppurative Otitis Media. All the patients included in the study population were subjected to thorough history taking, detailed clinical examination, including tuning fork tests, otoscopic examination, EUM (Examination Under Microscope), audiometric investigation in the form of PTA (Pure Tone Audiometry) \& radiological investigation.

\section{RESULTS}

The study found that 31-40 years was most commonly involved age group with female preponderance. Rural population mostly suffered from CSOM with left ear being more commonly involved. Purulent discharge was the commonest symptom with total perforation of tympanic membrane being the commonest presentation. Audiometry showed that $65.56 \%$ of the patients suffered from conductive type of hearing loss.

\section{CONCLUSIONS}

The study concluded that CSOM is a major health problem in the society involving all age groups with tubo-tympanic type being more common. Majority of the patients belongs to rural area and lower socioeconomic status with poor living standards with otorrhoea being the commonest presentation.

\section{KEY WORDS}

CSOM, Tympanic Membrane, Total Perforation, Conductive Type of Hearing Loss
Corresponding Author: Dr. Surajit Basumatari, C/o. Dr. N. Basumatari, House No. 36, Bye Lane No. 3, Sankar Dev Path, Rupnagar, Guwahati-781032, Dist., Kamrup Metro, Assam, India. E-mail: surajeetbasu.sb@gmail.com

DOI: $10.14260 / \mathrm{jemds} / 2019 / 603$

Financial or Other Competing Interests: None.

How to Cite This Article:

Basumatari S, Rajbangshi B. Sociodemographic profile of CSOM- a hospital based prospective study. J. Evolution Med. Dent. Sci. 2019;8(36): 2778-2782, DOI:
Submission 08-04-2019,

Peer Review 21-08-2019,

Acceptance 28-08-2019,

Published 09-09-2019. 


\section{BACKGROUND}

Chronic suppurative otitis media (CSOM) is one of the most common ear conditions in developing countries particularly in South-East Asian countries. Chronic otitis media has been an important disorder of middle ear causing morbidity and mortality since prehistoric times. Even with advent of newer antibiotics and better health facilities, chronic otitis media is still a widely encountered clinical entity in our country. Prevalence surveys, which vary widely in disease definition, sampling methods, and methodologic quality, show that the global burden of illness from CSOM involves 65-330 million individuals with draining ears, $60 \%$ of whom (39-200 million) suffer from significant hearing impairment. CSOM accounts for 28000 deaths and a disease burden of over 2 million DALYs. Over $90 \%$ of the burden is borne by countries in the South-east Asia and Western Pacific regions, Africa, and several ethnic minorities in the Pacific Rim affecting both the sexes $\&$ all age groups. ${ }^{1}$ A recent study shows prevalence of chronic otitis media in rural Indian population to be 46 per 1000 and in urban population is 16 per 1000.1

Chronic otitis media is defined as chronic inflammation of the lining epithelium of the middle ear cleft and mastoid cavity, characterized by persistent or intermittent otorrhoea through persistent non-intact tympanic membrane. A unifying definition of the term "Chronic Otitis Media" is any structural change in the middle ear system associated with a permanent defect in the Tympanic Membrane (TM). The condition is considered "Chronic," if the TM defect is present for a period greater than 3 months. Chronic otitis media results from long term Eustachian tube dysfunction with a poorly aerated middle -ear space, multiple bouts of acute otitis media, persistent middle-ear infection, allergy or other chronic inflammatory stimulus. ${ }^{2}$ Chronic Suppurative Otitis Media often begins as an acute infection of the middle ear, acute otitis media (AOM), which occurs in up to $80 \%$ of children by the age of 3 . While most cases resolve spontaneously, a small minority of patients progress to a chronic phase characterised by chronic purulent ear discharge through a perforated tympanic membrane with associated inflammation of the mastoid and middle ear mucosa and hearing loss. Chronic Suppurative Otitis Media can occur with or without cholesteatoma (Epithelial inclusion cyst).

The pathogenesis of Chronic Suppurative Otitis Media remains poorly understood. Complex interactions between the environment, microbes, and host are thought to lead to the development of this multifactorial disease Risk factors that have been attributed to the high rates of Chronic Suppurative Otitis Media in these populations are: overcrowding, poor hygiene, poor nutrition, high rates of nasopharyngeal colonization with potentially pathogenic bacteria and inadequate and unavailable health care. ${ }^{1}$

With the greater advent of diagnostic tools, it has become easier to diagnose and classify different types of chronic otitis media. Similarly, with easier availability of medicines and advanced surgical procedures the management of chronic otitis media has become easier. However, in developing nation like India \& particularly in lower Assam district of Barpeta and surrounding areas, Chronic Suppurative Otitis Media still accounts for major percentage of patients attending ENT OPD of FAAMCH. Therefore, this study aims to study the clinical profile of the patients of Chronic Suppurative Otitis Media and to analysis the epidemiological factors associated with CSOM.

\section{METHODS}

This is a hospital based cross sectional study in the department of ENT, Fakhruddin Ali Ahmed Medical College, Barpeta for a period of one year from $1^{\text {st }}$ January 2018 to $31^{\text {st }}$ December 2018. All the patients of Chronic Suppurative Otitis Media attending the OPD of department of ENT, FAAMCH, Barpeta after fulfilling the inclusion and exclusion criteria were included in the study.

\section{Selection of Cases}

All the cases of Chronic Otitis Media irrespective of age, sex, caste, religion, duration of illness \& severity of illness attending the Outpatient Dept. \& Inpatient Dept. of Otorhinolaryngology of Fakhruddin Ali Ahmed Medical College and Hospital, Barpeta by taking detailed history \& proper clinical examination.

\section{Inclusion Criteria}

- Patients with history of chronic discharging ear both unilateral \& bilateral with perforation of tympanic membrane diagnosed as tubo-tympanic type of Chronic Suppurative Otitis Media.

- Patients with history of chronic discharging ear both unilateral \& bilateral with perforation or retraction of tympanic membrane with or without cholesteatoma diagnosed as atticoantral type of Chronic Suppurative Otitis Media.

- Patients with history of hearing impairment (Documented with Pure Tone Audiometry, PTA) with previous history of discharge from ears with diagnosis of Chronic Suppurative Otitis Media.

- Patients presenting with features of complications of Chronic Suppurative Otitis Media either intracranial or extracranial.

\section{Exclusion Criteria}

- All patients of Acute Suppurative Otitis Media with perforation.

- Traumatic perforation of tympanic membrane.

- Patients presenting with otorrhoea and/or earache and/or decrease hearing with diagnosis of otomycosis or wax in the ear.

\section{Methodology}

All the patients included in the study population shall be subjected to thorough history taking, detailed clinical examination including tuning fork tests, Otoscopic examination, EUM (Examination under microscope), audiometric investigation in the form of PTA (Pure Tone Audiometry) \& radiological investigation. Radiological investigations include X-Ray Mastoid (Law's lateral oblique view), HRCT Scan of temporal bone in cases of suspected features of complications of CSOM. 


\section{RESULTS}

\begin{tabular}{|c|c|c|}
\hline Age in Years & No. of Patients & \% of Patients \\
\hline$<10$ & 17 & 9.44 \\
\hline $11-20$ & 31 & 17.2 \\
\hline $21-30$ & 35 & 19.4 \\
\hline $31-40$ & 45 & 25 \\
\hline $41-50$ & 40 & 2.22 \\
\hline$>51$ & 12 & 6.67 \\
\hline \multicolumn{3}{|c|}{ Table 1. Age Distribution } \\
\hline \multicolumn{3}{|c|}{} \\
\hline
\end{tabular}

\begin{tabular}{|c|c|}
\hline Sex & No. of Patients \\
\hline Male & $77(42.78 \%)$ \\
\hline Female & $103(57.2 \%)$ \\
\hline \multicolumn{2}{|c|}{ Table 2. Sex Distribution } \\
\hline
\end{tabular}

\begin{tabular}{|c|c|}
\hline Type of Population & No. of Patients \\
\hline Rural & $152(84.44 \%)$ \\
\hline Urban & $28(15.5 \%)$ \\
\hline Table 3. Distribution of Rural vs Urban Population \\
\hline
\end{tabular}

\begin{tabular}{|c|c|}
\hline Clinical Features & No. of Patients \\
\hline Ear discharge only & $47(26.1 \%)$ \\
\hline Hearing loss only & $21(11.67 \%)$ \\
\hline Ear discharge + hearing loss & $42(23.33 \%)$ \\
\hline $\begin{array}{c}\text { Ear discharge + hearing loss + earache/ } \\
\text { tinnitus/ear itching }\end{array}$ & $58(32.22 \%)$ \\
\hline Ear discharge + complications & $12(6.67 \%)$ \\
\hline \multicolumn{2}{|c|}{ Table 4. Distribution of Clinical Presentation } \\
\hline
\end{tabular}

\begin{tabular}{|c|c|}
\hline Associated Features & No. of Patients \\
\hline DNS & $41(22.78 \%)$ \\
\hline Adenoid hypertrophy & $23(12.78 \%$ \\
\hline Tonsillitis & $52(28.89 \%)$ \\
\hline Pharyngitis & $43(23.89 \%)$ \\
\hline Sinusitis & $89(49.44 \%)$ \\
\hline Aural polyp & $28(15.55 \%)$ \\
\hline \multicolumn{2}{|c|}{ Table 5. Distribution of Associated Clinical Features } \\
\hline
\end{tabular}

\begin{tabular}{|c|c|}
\hline Side Involved & No. of Patients \\
\hline Right & $61(33.89 \%)$ \\
\hline Left & $83(46.11 \%)$ \\
\hline Bilateral & $36(20 \%)$ \\
\hline Table 6. Distribution of Side of Ear involved at Presentation \\
\hline
\end{tabular}

\begin{tabular}{|c|c|}
\hline Characteristic of Ear Discharge & No. of Patients \\
\hline Discharge Type & $74(41.11 \%)$ \\
Purulent & $48(26.67 \%)$ \\
Mucopurulent & $31(17.22 \%)$ \\
Mucoid & $27(15 \%)$ \\
Blood stained & \\
Amount & $113(62.78 \%)$ \\
Profuse & $67(37.22 \%)$ \\
Scanty & $98(54.44 \%)$ \\
Odour & $82(45.55 \%)$ \\
Foul smell + & Foul smell - \\
\hline \multicolumn{2}{|c|}{ Table 7. Characteristics of Ear Discharge and its Distribution } \\
\hline
\end{tabular}

\begin{tabular}{|c|c|}
\hline Duration in Months & No. of Patients \\
\hline$<12$ & $31(17.2 \%)$ \\
\hline $13-24$ & $37(205 \%)$ \\
\hline $25-36$ & $48(26.67 \%)$ \\
\hline $37-48$ & $24(13.33 \%)$ \\
\hline $49-60$ & $19(10.5 \%)$ \\
\hline$>61$ & $21(11.67 \%)$ \\
\hline \multicolumn{2}{|c|}{ Table 8. Duration of Discharge } \\
\hline
\end{tabular}

\begin{tabular}{|c|c|}
\hline Type of Perforation & No. of Patients \\
\hline Small perforation $(<25 \%)$ & $18(10 \%)$ \\
\hline Medium $(25-50 \%)$ & $24(13.33 \%)$ \\
\hline Large $(50-75 \%)$ & $29(16.11 \%)$ \\
\hline Subtotal $(>75 \%)$ & $31(17.22 \%)$ \\
\hline Total & $46(25.56 \%)$ \\
\hline Marginal & $21(11.67 \%)$ \\
\hline Attic & $11(6.11 \%)$ \\
\hline Table 9. Distribution of Types of Tympanic Membrane Perforation \\
\hline
\end{tabular}

\begin{tabular}{|c|c|}
\hline Type of Hearing Loss & No. of Patients \\
\hline Conductive hearing loss & $118(65.56 \%)$ \\
\hline Sensorineural hearing loss & $24(13.33 \%)$ \\
\hline Mixed hearing loss & $38(21.11 \%)$ \\
\hline \multicolumn{2}{|c|}{ Table 10. Distribution of Audiological Findings } \\
\hline
\end{tabular}

\section{DISCUSSION}

Chronic Suppurative Otitis Media is a major public-health problem, and India is one of the countries with highprevalence where urgent attention is needed. It is a persistent disease with great risk of irreversible complications. Chronic Suppurative Otitis Media is an important cause of preventable hearing loss particularly in the developing world and a reason of serious concern, particularly in children, because it may have long-term effects on early communication, language development, auditory processing, educational process, and physiological and cognitive development which in turn has substantial economic burden on the health care system. Poor living conditions, overcrowding, poor hygiene and nutrition have been suggested as a basis for the widespread prevalence of Chronic Suppurative Otitis Media in developing countries.

This hospital based prospective study analysed the clinical profile and epidemiological factors associated with Chronic Suppurative Otitis Media in 180 patients fulfilling the inclusion and exclusion criteria for a duration of 1 year in the dept. of otorhinolaryngology, FAAMCH Barpeta.

The study found that 31-40 years was most commonly involved age group with $25 \%$ cases belonging to it. $9.4 \%$ of the cases were less than 10 years while $6.67 \%$ cases were more than 51 years. Indorewala et al in their study found that the age of the patients ranged from 5 to 76 years with a mean age of $35 \pm 15.8$ years; the age group 21 - 40 years was the most affected group (36\%). ${ }^{3}$

The male to female ratio was $0.75: 1$ which indicates female preponderance over male. Browning et al found the incidence of CSOM to be $1.9 \%$ in male and $1.2 \%$ in female. ${ }^{4}$

The study observed that $84.4 \% \%$ of the cases belonged to rural population while $15.5 \% \%$ cases were from urban locality. The study by Maharjan et al reflected that the prevalence of Chronic Suppurative Otitis Media is high in rural communities of Nepal, Bangladesh and aboriginal children of Northern and central Australia. Probably, the habit of swimming in polluted water in a pond or river regularly may be a factor responsible for discharging ear. ${ }^{5}$

The reason for higher incidence in the rural area could be due to lower standard living, poor hygiene, malnutrition, illiteracy, negligence on the part of patient and family members and lack of proper medical facilities in the rural areas.

It was observed that left ear was commonly involved ( $46.11 \%$ of the cases) followed by right ear in $33.89 \%$ cases and bilateral involvement was seen in $20 \%$ cases. Similar to our study, Shivakumar et al also found that left side was more commonly involved than the right side. ${ }^{6}$ Saha et al in their study found bilateral ear disease in 30\% cases. Right ear disease was in $20 \%$ and left ear disease was in $50 \%$ of the cases. $^{7}$ However, no explanation has been given for more involvement of left ear than right ear. 
In the study, we found that otorrhoea along with other symptoms like hearing loss and/or itching and/or earache and/ or tinnitus was the most common presenting symptom (32.22\%). This was followed by otorrhoea only $(26.1 \%)$, otorrhoea with hearing loss (23.3\%), hearing loss only (11.67\%). 6.67\% cases presented with complications of CSOM. Kumaret al observed that otorrhoea was the commonest complaint with $81.25 \%$ patients presented to hospital, followed by hearing impairment in $62.50 \%$, itching in the ear in $9.37 \%$, tinnitus in $18.75 \%$, trauma to the ear in $7.81 \%$ cases and earache in $3.12 \%$ cases. $^{8}$

Shettyet al in their study found that commonest presenting complaints was ear discharge and hearing loss seen in all the $(100 \%)$ patients. Tinnitus was found in $15 \%$, earache in $33.3 \%$ and vertigo in $11.3 \%$ of patients. ${ }^{9}$

$24 \%$ of cases had associated DNS. Adenoid hypertrophy was seen in $5 \%$ cases. Upper respiratory tract infection was present in the form of pharyngitis $19 \%$ ) cases \& tonsillitis $(14 \%)$ cases. Sinusitis was present in $13 \%$ cases. $12 \%$ cases had associated aural polyp.

Analysis of characteristics of the ear discharge showed that $41.11 \%$ cases had purulent discharge. This was followed by mucopurulent $(26.67 \%)$, mucoid $(17.2 \%)$ and bloodstained discharge (15\%). Profuse otorrhoea was seen in $62.78 \%$ cases while scanty discharge was present in $37.2 \%$ cases. $54.4 \%$ cases had foul smelling discharge. Islam et al observed that $66.6 \%$ cases had purulent ear discharge. This was followed by blood stained discharge in $23.33 \%$ of cases, mucopurulent discharge in $6.66 \%$ cases and mucoid discharge in $3.33 \%$ of the total cases. ${ }^{10}$

History of otorrhoea for less than 1 year was seen in $17.2 \%$ cases. $20.5 \%$ cases had otorrhoea for 13-24 months. $26.67 \%$ cases history of ear discharge for 25-36 months. $13.33 \%$ cases had history of ear discharge for 37-48 months. Koloet al observed that the range of duration of ear discharge varied from 14 months to 20 years with mean duration 8.515 years (SD 8.599). ${ }^{11}$

Otoscopic examination \& Examination under Microscope revealed that total perforation of tympanic membrane was seen in $25.56 \%$ cases. $17.22 \%, 16.11 \%, 13.33 \%$ \& $10 \%$ cases had subtotal, large, medium and small Tympanic Membrane perforation respectively. Attic perforation \& marginal perforation was seen in $6.11 \%$ \& $11.67 \%$ respectively. However, Kumar et al in their study observed that $43.75 \%$ had medium tympanic membrane perforation, $14.06 \%$ had large TM perforation and $32.81 \%$ had subtotal tympanic membrane perforation. ${ }^{8}$

In the study we observed that $65.56 \%$ cases had conductive hearing loss. Sensorineural hearing loss and mixed hearing loss was seen in $13.33 \%$ \& $21.11 \%$ cases respectively.

\section{CONCLUSIONS}

The study concludes that chronic suppurative otitis media is still a major health problem in this part of the country. Individuals belonging to all age groups more or less suffer from CSOM. Tubo-tympanic variant is more common than atticoantral type. Overall female preponderance has been observed in the study probably due to lack of proper medical care in early stages in the rural areas. Majority of the patients belongs to rural area and lower socioeconomic status with poor living standards along with traditional habit of taking bath in ponds and other water bodies. This can be attributed to higher incidence of Chronic Suppurative Otitis Media in Barpeta and adjoining area in lower Assam districts. Otorrhoea is the commonest clinical presentation of Chronic Suppurative Otitis Media. Majority of the patients have purulent ear discharge. Otorrhoea is followed by wide clinical presentations like decreased hearing (conductive hearing loss), itching in the ear, earache, tinnitus and features of complications like vertigo have been observed in our study. Otoscopic examination showed total perforation of tympanic membrane as the commonest clinical finding. Presence of nidus of infection in the upper airway in the form of pharyngitis, tonsillitis or sinusitis has been seen to be associated with Chronic Suppurative Otitis Media. By improving the living standards, health care facilities \& awareness among the population particularly in lower socioeconomic class and rural areas, the incidence \& prevalence of Chronic Suppurative Otitis Media (CSOM) can be reduced. This in turn will help in substantial reduction in morbidity associated with chronic suppurative otitis media i.e. hearing loss which subsequently eases the social and economic burden on the health care delivery system of our country.

\section{REFERENCES}

[1] WHO. Chronic suppurative otitis media burden of illness and management options. Geneva: World Health Organization 2004

[2] Gopen Q. Pathology and clinical course of the inflammatory diseases of the middle ear. In: Gulya AJ, edr. Glasscock-Shambaugh surgery of the ear. $6^{\text {th }}$ edn. Shelton, CT: People's Medical Publishing House 2010: p. 425-36.

[3] Indorewala S, Adedeji TO, Indorewala A, et al. Tympanoplasty outcomes: a review of 789 cases. Iran J Otorhinolaryngol 2015;27(79):101-8.

[4] Browning GG, Gatehouse S, Calder IT. Medical management of active chronic otitis media: a controlled study. J Laryngol Otol 1988;102(6):491-5.

[5] Maharjan M, Bhandari S, Singh I, et al. Prevalence of otitis media in school going children in eastern Nepal. Kathmandu Univ Med J 2006;4(4):479-82.

[6] Shivakumar KL, Joshym S, Mary. Role of cortical mastoidectomy in inactive, mucosal type of chronic otitis media. Journal of evidence based medicine and healthcare 2014;1(7):509-17.

[7] Saha AK, Munsi DM, Ghosh SN. Evaluation of improvement of hearing in type I tympanoplasty \& its influencing factors. Indian J of Otolaryngology and Head and Neck Surgery 2006;58(3):253-7.

[8] Kumar N, Chilke D, Puttewar MP. Clinical profile of tubotympanic CSOM and its management with special reference to site and size of tympanic membrane perforation, Eustachian tube function and three flap tympanoplasty. Indian J Otolaryngol Head Neck Surg 2012;64(1):5-12.

[9] Shetty S. Pre-operative and post-operative assessment of hearing following tympanoplasty. Indian J Otolaryngol Head Neck Surg 2012;64(4):377-81. 
[10] Islam M, Taous A, Hossain M, et al. Comparative study of tubotympanic and atticoantral variety of chronic suppurative otitis media. Bangladesh $\mathrm{J}$ of Otorhinolaryngology 2010;16(2):113-9.
[11] Kolo ES, Ramalingam R. Hearing results post tympanoplasty: our experience with adults at the KKR ENT hospital, India. Indian J Otolaryngol Head Neck Surg 2014;66(4):365-8. 